in that in the resected specimen in Case 3 there were numerous red patches on the antimesenteric border of the descending colon. These were acutely congested patches that had not actually infarcted, and in Case 4 similar patches in the sigmoid colon actually showed full-thickness necrosis which had not perforated, presumably because of the proximal perforation.

Why these lesions should be more common in the colon than in the small bowel is difficult to explain if the condition is due to vascular changes resulting from back pressure. Cases 1, 3, and 4 perforated in inferior mesenteric vein territory, but Case 2 involved superior mesenteric vein territory, and Schaffer (1960) described a case in which there was an "unexpectedly excellent result" in a "miracle baby" who had two ileal perforations closed at laparotomy, and these occurred after an exchange transfusion. More small-bowel perforations may be reported once the association between bowel perforation and exchange transfusion becomes more appreciated; but it may be that the more complex venous system of the small bowel damps down any sudden rises in portal pressure more effectively than the large-bowel venous system. Continuous monitoring of the injection pressure during exchange transfusion could avoid large and dangerous pressure variations.
REFERENCES

Boikan, W. S. (1930). Arch. Path., 9, 1164

Farquhar, J. W., and Smith, H. (1958). Arch. Dis. Childh., 33, 142. Forshall, I. (1964). 4th Liverpool Lecture (British Association of Pacdiatric Surgeons 11th International Congress, Rotterdam).

Haas, L. (1958). Arch. Dis. Childh., 33, 362.

Helbing, T. (1908). Ueber foetale Peritonitis, nebst einem casuistischen Beitrag aus der Universitäts Frauenklinik zu Freiburg. Freiburg.

Hermann, R. E. (1965). Surgery, 58, 436.

Johnston, T. B., and Whillis, J. (1949). Gray's Anatomy, 30th ed., p. 704. London.

Lattes, R. (1943). Amer. F. Obstet. Gynec., 46, 149.

Levin, S. E., and Isaacson, C. (1960). Arch. Dis. Childh., 35, 378.

Linkner, L. M., and Benson, C. D. (1959). Ann. Surg., 149, 525.

Lister, J. (1964). Arch. Dis. Childh., 39, 131.

Maguire, C. H., and Moore, W. R.'(1950). Surgery, 28, 568.

Mintz, A. A., and Vallbona, C. (1960). Pediatrics, 26, 661.

Moretti, I. (1949). Minerva pediat., 1, 239.

Nienhuis, I I (1963). Amer. Surg., $29,835$.

Paltauf, A. (1888). Virchows Arch. path. Anat., 111, 461.

Schaffer, A. J. (1960). Diseases of the Newborn, p. 350. Philadelphia.

Schaffer, A. J. (1960). Diseases of the Newborn, p. 350. Philadelphia.
Sury, K. von (1912). Vischr. gerichtl. Med., 43, Suppl. No. 2, p. 91 .

Sury, K. von (1912). Vischr. gerichtl. Med., 43, Suppl. No. 2, p. 91.

van Loghem, J. J., van Bolhuis, J. H., Soeters, J. M., and Veeneklaas, G. M. H. (1949). Brit. med. $\dot{f} ., 2,49$.

Wagget, J. (1968). British Association of Paediatric Surgeons, 15th International Congress, Liverpool.

Waldhausen, J. A., Herendeen, T., and King, H. (1963). Surgery, 54, 365.

Zachary, R. B. (1957). Arch. Dis. Childh., 32, 22.

\title{
Perforation of the Bowel in the Newborn as a Complication of Exchange Transfusion
}

\author{
R. L'E. ORME,* M.A., M.R.C.P., D.C.H. ; SHEILA M. EADES, † M.R.C.P.ED, D.C.H.
}

Brit. med. F., 1968, 4, 349-351

\begin{abstract}
Cummary: Spontaneous perforation of the bowel $\checkmark$ without evidence of intestinal obstruction is reported in six infants who had exchange transfusions for rhesus incompatibility, and in a seventh who had prolonged intravenous fluids via the umbilical vein. The pathological findings resemble those found in acute necrotizing enterocolitis in adults, which is known to be associated with arterial hypotension. The cause in these infants may also be due to a period of hypotension during the transfusion, and hypoxia and superimposed infection may also play an important part.
\end{abstract}

\section{Introduction}

"Spontaneous" perforation of the bowel in the newborn, where perforation occurs in the absence of intestinal obstruction, was first described by Siebold (1826). Thelander (1939) reviewed the world literature up to 1939 . Of her 85 cases 65 occurred in the neonatal period. Thomas and Brockman (1966) found 26 further cases in the colon between 1946 and 1965, and Fonkalsrud et al. (1966) reported 19 cases of "spontaneous" perforation in a study of neonatal peritonitis. Some of the earlier cases may have been associated with meconium ileus due to cystic fibrosis or Hirschsprung's disease.

We describe six cases of "spontaneous" perforation in newborn infants who had had exchange transfusions shortly beforehand.

\section{Case 1}

A male infant weighing $3.2 \mathrm{~kg}$. was delivered normally following induction at 36 weeks. The mother's blood group was $\mathbf{O}$ negative

* Senior Registrar in Paediatrics, Devon and Exeter Clinical Area. t Consultant Paediatrician, Devon and Exeter Clinical Area. with rhesus antibodies present 1 in 40 . There was no asphyxia at birth. Cord blood results were: group $\mathrm{O}$ positive ; Coombs test positive; $\mathrm{Hb} 70 \%$; bilirubin $9.7 \mathrm{mg} . / 100 \mathrm{ml}$. Three exchange transfusions were carried out without difficulty in the first 48 hours, calcium supplements being given. No antibiotics were used.

At the age of 54 hours he became reluctant to feed and passed small quantities of bright blood rectally. Abdominal distension developed. Bowel sounds were normal. At 72 hours periumbilical oedema and erythema developed. Portal vein thrombosis was suspected. An abdominal $x$-ray picture was suggestive of ileus. There was no gas under the diaphragm.

Laparotomy at 130 hours showed faecal peritonitis with two perforations of the large bowel, in the caecum and descending colon. The affected bowel was resected and an ileostomy fashioned. Postoperative recovery was good. Microscopy. (Fig. 1) showed an acute colitis with extensive necrosis of the mucosa and submucosa. Associated vessels were thrombosed, but it was not possible to say whether this was primary or secondary.

\section{Case 2}

A male infant weighing $3 \mathrm{~kg}$. was delivered by lower segment caesarean section for foetal distress after induction at 38 weeks. The liquor was meconium-stained. The infant had white asphyxia and required endotracheal oxygen for resuscitation. Maternal blood group: A negative, with antibodies 1 in 20 . Cord blood: group $\mathrm{O}$ positive; Coombs test positive; $\mathrm{Hb} 85 \%$. Exchange transfusion was carried out at three hours with calcium supplements. Streptomycin was given.

At the age of 4 days the infant developed bilious vomiting and passed blood and mucus rectally. Abdominal distension, grunting respiration, and periumbilical oedema and erythema followed. Bowel sounds were absent and peritonitis was suspected. An $x$-ray film of the abdomen showed gas under the diaphragm. At operation three large perforations were found in the sigmoid colon. The affected bowel was resected with an end-to-end anastomosis. 
He died eight days postoperatively. Microscopy showed that near the perforations the whole colonic wall was necrotic, haemorrhagic, and densely infiltrated with polymorphs. Further away there was less inflammation, but deep necrotizing ulcers were destroying isolated sections of mucosae, muscularis mucosa, and submucosa.

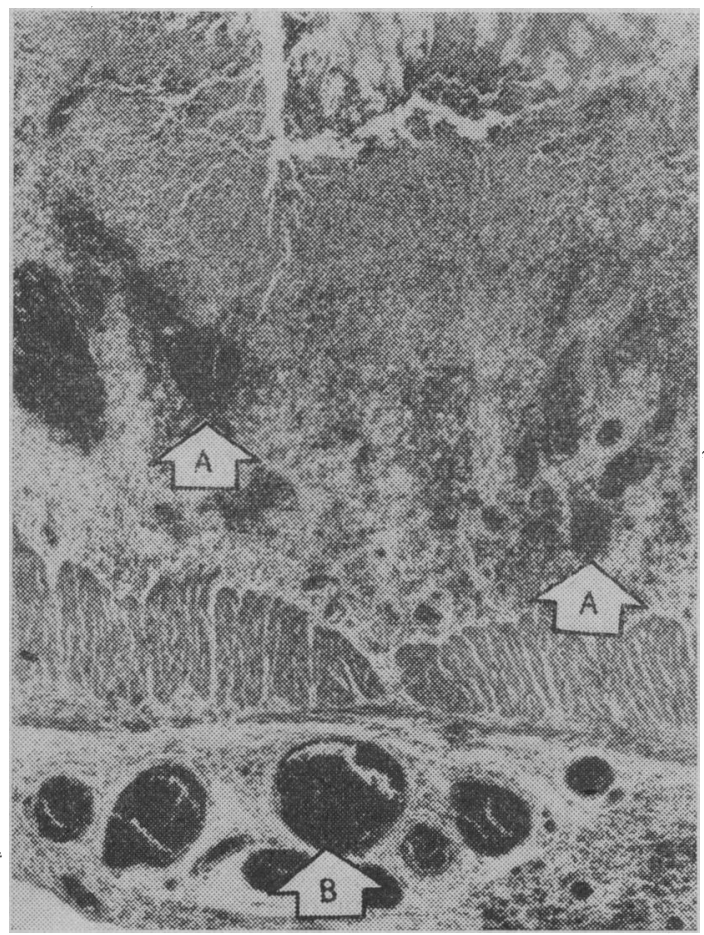

Case 1. Full width of bowel wall to show haemorrhagic necrosis of mucosa and submucosa (A) and thrombosis of serosal blood vessels (B).

\section{Case 3}

This female infant weighing $3 \mathrm{~kg}$. had a normal delivery at 38 weeks. There was no birth asphyxia. The mother's blood group was rhesus negative with antibodies. Cord blood results: Coombs test strongly positive; $\mathrm{Hb} 82 \%$; bilirubin $3.2 \mathrm{mg} . / 100 \mathrm{ml}$. An exchange transfusion was carried out at two hours. Oxygen was required during the procedure. On the fourth day abdominal distension and bilious vomiting developed. She continued to pass meconium but no blood. $X$-ray examination of the abdomen showed fluid levels. At operation multiple gangrenous areas of bowel necessitated resection of 6 in. $(15 \mathrm{~cm}$.) of jejunum, 7 in. $(17.5 \mathrm{~cm}$.) of ileum, and $7 \mathrm{in},(17.5 \mathrm{~cm}$.) of transverse colon. Postoperative recovery was excellent, and when last seen, aged 3 years, she was well. Microscopy showed extensive necrosis of the mucosa, which extended into the submucosa and in places through the entire wall. Haemorrhage into the coats of the gut and a mononuclear exudate into the serosa were found. There was no evidence of mesenteric thrombosis. The appearances were compatible with a diagnosis of acute necrotizing enterocolitis.

\section{Case 4}

This infant, a female weighing $2.6 \mathrm{~kg}$., was severely asphyxiated at birth and required two exchange transfusions for rhesus incompatibility. At the age of 4 days she developed vomiting and abdominal distension but still passed meconium. A straight $x$-ray film of the abdomen did not show obstruction. The symptoms subsided and she was discharged home at two weeks. However, vomiting and frequent loose motions recurred later, and $x$-ray films now showed fluid levels. A barium enema demonstrated an ileocolic fistula. At operation two loops of ileum and jejunum were adherent to the splenic flexure. Each of these communicated separately with the lumen of the colon. The affected length of colon was excised and the holes in the small bowel were closed. Microscopy showed that the perforations were lined by necrotic tissue infiltrated with acute inflammatory cells. The intramural nerve plexuses were normal. Subsequent rectal biopsy confirmed this.

\section{Case 5}

A female infant weighing $2.1 \mathrm{~kg}$. was delivered normally following induction at 34 weeks. Maternal group $\mathbf{A}$ negative with antibodies 1 in 256. Cord blood results: group A positive; Coombs test positive; $\mathrm{Hb} 92 \%$; bilirubin $4.5 \mathrm{mg} . / 100 \mathrm{ml}$. Exchange transfusions were carried out on the third and fourth days, the first with some difficulty. Signs of intestinal obstruction now developed, with vomiting and abdominal distension, which was treated conservatively with gastric aspiration and intravenous fluids. After an initial improvement she collapsed and died. Necropsy showed multiple perforations of the bowel.

\section{Case 6}

This male infant weighing $2.4 \mathrm{~kg}$. was delivered normally. The maternal blood group was rhesus negative with antibodies. Cord blood: Coombs test positive ; $\mathrm{Hb} 84 \%$; bilirubin $3.5 \mathrm{mg} . / 100 \mathrm{ml}$. Two exchange transfusions were performed, at 41 and 65 hours. At the age of 6 days bilious vomiting and abdominal distension developed. Bowel sounds were absent. At laparotomy a large perforation of the transverse colon was found and closed. Postoperative recovery was complicated by a faecal fistula. At the age of 3 months a second episode of obstruction was found to be due to adhesions and a Richter's hernia of, the proximal duodenum. Since the second operation he has thrived. Pathological findings are not available.

We also record a seventh case in which prolonged intravenous fluids via the umbilical vein were given, but no exchange transfusion.

\section{Case 7}

This infant, a male weighing $1.5 \mathrm{~kg}$., was born into a bucket in a caravan. On his admission the rectal temperature was $82^{\circ} \mathrm{F}$. $\left(27.8^{\circ}\right.$ C.), pulse 80 . The temperature rose to $92^{\circ} \mathrm{F}$. $\left(33.3^{\circ} \mathrm{C}\right.$.) over eight hours. Antibiotics were given.

At 12 hours he became apnoeic and was treated with intermittent positive-pressure respiration and dextrose via umbilical vein catheter. A chest $x$-ray film showed hyaline membrane appearances. On the third day jaundice developed, the bilirubin reaching $12 \mathrm{mg} . / 100 \mathrm{ml}$ No blood group incompatibility was demonstrated. Attempts to wean the infant off the respirator failed and he died aged 7 days. Necropsy revealed a perforation of the ileum, and microscopy showed non-specific inflammation and necrosis, reported by the pathologist as similar to those in Case 1.

We have found four other cases associated with exchange transfusion in the literature (Nienhuis, 1963 ; Waldhausen et al., 1963 ; Hermann, 1965 ; Schaffer, 1965). In Nienhuis's case the perforation was thought to have occurred in utero and thus would have preceded the transfusion.

\section{Clinical Manifestations}

Though spontaneous perforation of the bowel in the newborn is well documented we believe insufficient emphasis has been laid on the early manifestations, which may lead to a mistaken diagnosis. We think it helpful to divide these into two groups, early and late, as follows:

(a) Early.-(1) Refusal to feed. (2) Passage of blood and mucus rectally. (3) Abdominal distension. (4) Bilious vomiting. (5) Absent bowel sounds. $X$-ray examination of the abdomen may be normal at this stage or show distended loops of bowel (Case 1 and the case described by Hermann, 1965).

(b) Later, after perforation has occurred.-(1) Erythema and oedema of the anterior umbilical wall. This may suggest a diagnosis of umbilical sepsis and cellulitis, or portal pyaemia and thrombosis in a baby who has had umbilical catheterization. (2) Grunting. (3) Pallor. (4) Hypothermia. (5) Peripheral circulatory failure. $X$-ray examination of the abdomen now shows gas under the diaphragm. 


\section{Discussion}

The aetiology of this condition has never been satisfactorily elucidated. A variety of possible causes have been suggested, including congenital weakness of the bowel wall (Rudnew, 1915; Fischer, 1928 ; Boikan, 1930) and trauma (Fonkalsrud et al., 1966). Infection, either generalized septicaemia or primary peritonitis, has been incriminated (Waldhausen et al., 1963 ; Hermann, 1965; Thomas and Brockman, 1966). Hypoxia due to asphyxia or the respiratory distress syndrome is a factor (Lloyd et al., 1964 ; Thelander, 1939).

We think that in our cases the association between exchange transfusion and subsequent perforation is more than coincidental and that the cause is likely to be vascular, related to local vasomotor disturbances, or systemic hypotension exacerbated by hypoxia.

The term "necrotizing enterocolitis" has been used to describe the pathological findings in these infants (Waldhausen et al., 1963 ; Hermann, 1965 ; Fonkalsrud et al., 1966). The lesions in this condition are diffuse non-specific areas of necrosis with acute inflammation, which has not followed obstruction to a major blood vessel supplying the bowel. Hermann (1965) believed that this was due to an anaphylactic reaction of the Shwartzman type. This requires a sensitizing dose of antigen locally, followed after an interval by a second dose intravenously, causing necrosis at the site of the sensitizing dose. In this case sensitization of the bowel wall by bacteria could occur during colonization of the bowel. Umbilical catheterization later could introduce further bacteria into the circulation.

However, necrotizing enterocolitis has been widely described in elderly adults, and in them its association with hypotension is well recognized. McGovern and Goulston (1965) described 33 cases of "ischaemic enterocolitis," in 19 of which hypotension was recognized before the onset of symptoms, and in another seven in which they considered there was microscopical evidence of hypotension in the form of zonal necrosis of the liver or epithelial necrosis in the proximal renal tubules. Kay et al. (1958) described another 16 cases, all of which were associated with an acute hypotensive episode, though these authors suspected that the colitis preceded rather than followed the hypotension. Marston (1962) has postulated that, as arterioles obey Laplace's law, the smaller the blood vessel the narrower is the margin between rupture on the one hand and collapse on the other. Small falls in pressure in the mesenteric vessels can therefore exceed the critical closing pressure of minute vessels in the bowel wall and cause widespread shutdown. Because these vessels vary in length and position, and are affected by the tone and diameter of the bowel wall, the resulting changes may be patchy.
We can find no recorded evidence of systemic blood-pressure readings during exchange transfusion. We are endeavouring in this unit to monitor the blood pressure in the aorta during the procedure in some cases and hope to present our findings in a future paper.

Another possibility (Kay et al., 1958) is that the anatomy of the vessels in the bowel wall is such that shunting may take place, bypassing the mucosa. Such shunts are well recognized in the lung, and in the respiratory distress syndrome hypoxia increases the flow through the shunt. It is interesting to speculate that hypoxia might have a similar effect on shunts in the bowel wall. Once ischaemia has occurred bacteria in the bowel could proliferate and invade the bowel wall and the effect of their endotoxins might be superimposed. Coliform endotoxins are sympathomimetic, and, possibly by potentiating adrenaline, can bring about further vasoconstriction and ischaemia of the bowel wall (Lillehei, 1957).

We wish to thank Dr. F. S. W. Brimblecombe, Dr. Beryl Corner, Dr. R. H. Dobbs, Professor W. Gaisford, Dr. L. Haas, and Dr. Mary Wilmers for permission to quote cases in their care, and for their encouragement and advice. We are indebted to Dr. N. J. Brown, Dr. R. A. Caldwell, and Dr. N. France for the pathological findings, and to Dr. Sheila Lewis and Sister Mary Chase for help in tracing details of Case 6.

Requests for reprints should be addressed to S.M.E., North Devon Infirmary, Barnstaple.

\section{REFERENCES}

Boikan, W S. (1930). Arch. Path., 9, 1164.

Fischer, A. E. (1928). Amer. F. Dis. Child., 36, 774.

Fonkalsrud, E. W., Ellis, D. G., and Clatworthy, H. W. (1966). F. pediat. Surg., 1, 227.

Hermann, R. E. (1965). Surgery, 58, 436.

Kay, A. W., Richards, R. L., and Watson, A. J. (1958). Brit. F. Surg., 46, 45 .

Lillehei, R. C. (1957). Surgery, 42, 1043.

Lloyd, J. R., Bernstein, J., and Espiasse, E. (1964). Harper Hosp. Bull., 22, 224 .

McGovern, V. J., and Goulston, S. J. M. (1965). Gut, 6, 213.

Marston, A. (1962). Lancet, 2, 365.

Nienhuis, L. I. (1963). Amer. Surg., 29, 835.

Rudnew, W. (1915). Inaugural Dissertation. Basel.

Schaffer, A. J. (1965). Diseases of the Newborn. Philadelphia.

Siebold, A. E. (1826). F. für Geburtsh., 5, 3.

Swenson, O., Neuhauser, E. B. D., and Pickett, L. K. (1949). Pediatrics, 4,201 .

Thelander, H. E. (1939). Amer. F. Dis. Child., 58, 371.

Thomas, C. S., and Brockman, S. K. (1966). Ann. Surg., 164, 853. Waldhausen, J. A., Herendeen, T., and King, H. (1963). Surgery, 54, 